\title{
Neural Progenitor Cell Implants in the Lesioned Medial Longitudinal Fascicle of Adult Cats Regulate Synaptic Composition and Firing Properties of Abducens Internuclear Neurons
}

\author{
Camilo J. Morado-Díaz, Esperanza R. Matarredona, Sara Morcuende, Rocío Talaverón, \\ María A. Davis-López de Carrizosa, Rosa R. de la Cruz, and Angel M. Pastor \\ Departamento de Fisiología, Facultad de Biología, Universidad de Sevilla, 41012 Sevilla, Spain
}

\begin{abstract}
Transplants of neural progenitor cells (NPCs) into the injured CNS have been proposed as a powerful tool for brain repair, but, to date, few studies on the physiological response of host neurons have been reported. Therefore, we explored the effects of NPC implants on the discharge characteristics and synaptology of axotomized abducens internuclear neurons, which mediate gaze conjugacy for horizontal eye movements. NPCs were isolated from the subventricular zone of neonatal cats and implanted at the site of transection in the medial longitudinal fascicle of adult cats. Abducens internuclear neurons of host animals showed a complete restoration of axotomy-induced alterations in eye position sensitivity, but eye velocity sensitivity was only partially regained. Analysis of the inhibitory and excitatory components of the discharge revealed a normal re-establishment of inhibitory inputs, but only partial re-establishment of excitatory inputs. Moreover, their inhibitory terminal coverage was similar to that in controls, indicating that there was ultimately no loss of inhibitory synaptic inputs. Somatic coverage by synaptophysin-positive contacts, however, showed intermediate values between control animals and animals that had undergone axotomy, likely due to partial loss of excitatory inputs. We also demonstrated that severed axons synaptically contacted NPCs, most of which were VEGF immunopositive, and that abducens internuclear neurons expressed the VEGF receptor Flk1. Together, our results suggest that VEGF neurotrophic support might underlie the increased inhibitory-to-excitatory balance observed in the postimplant cells. The noteworthy improvement of firing properties of injured neurons following NPC implants indicates that these cells might provide a promising therapeutic strategy after neuronal lesions.
\end{abstract}

Key words: abducens; eye movements; motoneuron; oculomotor; plasticity

\section{Introduction}

Neuronal circuits are typically envisaged as providing a downstream flow of information, in the form of spikes, from afferent neurons to their target neurons, muscle fibers, or glands. However, it should be stressed that there is an equally important information flow that courses upstream in the form of targetderived factors, that is, retrogradely from the target tissue to the innervating cells (Chao, 2003; Rind et al., 2005). Whenever the trophic supply between connected cells is interrupted, for instance by axotomy, a number of deleterious effects appear,

Received Oct. 2, 2013; revised March 17, 2014; accepted April 16, 2014.

Author contributions: E.R.M., R.R.d.I.C., and A.M.P. designed research; C.J.M.-D., E.R.M., S.M., R.T., M.A.D.-L.d.C., and A.M.P. performed research; C.J.M.-D., E.R.M., S.M., R.T., M.D.-L.d.C., and R.R.d.I.C. analyzed data; R.R.d.I.C. and A.M.P. wrote the paper.

This work was supported by the Ministerio de Economía y Competitividad-Fondo Europeo de Desarrollo Regional Grants BFU2009-07121 and BFU2012-33975, and Junta de Andalucía Grant CVI-6053. Electron microscopy and cell culture was performed in the central research services of Universidad de Sevilla. We thank Dr. David Macías for providing us with the lentiviral vector. We also thank Dr. PaulJ. May for English language revisions in the manuscript. This article is dedicated to the memory of Professor Steve M. Highstein.

Correspondence should be addressed to Dr. Angel M. Pastor, Departamento de Fisiología, Facultad de Biología, Avenida Reina Mercedes, 6, 41012-Sevilla, Spain. E-mail: ampastor@us.es.

DOI:10.1523/JNEUROSCI.4231-13.2014

Copyright $\odot 2014$ the authors $\quad 0270-6474 / 14 / 347007-11 \$ 15.00 / 0$ ranging from cell death to a wealth of metabolic and electrophysiological changes that impact the synaptic and firing properties of neurons (Titmus and Faber, 1990). These alterations revert to a certain extent when new targets are provided (de la Cruz et al., 1996; Benítez-Temiño et al., 2005; Navarro et al., 2007). Moreover, individual factors derived from target neurons applied to the stump of the severed axons selectively regulate tonic and phasic firing properties (Davis-López de Carrizosa et al., 2009). Thus, those experiments indicate that the target is a powerful phenotypic regulator of the innervating neuron (Park and Poo, 2013).

As a proof of concept, we sought to deliver at the site of a central lesion in the medial longitudinal fascicle (MLF) neural progenitor cells that have the potential not only to integrate within the scaffold of cells in the host tissue (Cusimano et al., 2012; Fagerlund et al., 2012), but also to deliver trophic factors such as nerve growth factor (NGF), brain-derived neurotrophic factor (BDNF), neurotrophin-3 (NT-3), and vascular endothelial growth factor (VEGF; Tonchev et al., 2007). The synaptotrophic action of these factors is supported by the fact that their delivery modifies synaptic and discharge characteristics of neurons (Zhou et al., 2005; Boyce et al., 2012). Sectioning the MLF is a useful tool 
for affecting a well defined neuronal population, the abducens internuclear neurons, in a brainstem pathway for oculomotor control (Delgado-Garcia et al., 1986b). We have previously demonstrated that axotomized abducens internuclear neurons survive the interruption of their axons after transecting the MLF, but exhibit a series of long-lasting modifications of their discharge activity and synaptic inputs (de la Cruz et al., 2000), as they remain targetless (Pastor et al., 2000).

Here, we aimed to provide axotomized abducens internuclear neurons with neural progenitor cells implanted at the site of a lesion. Our findings indicate that neural progenitor cells are able to rescue, to a large extent, the discharge characteristics and afferent inputs of axotomized neurons, but with an imbalance in favor of inhibition. Likely, neurotrophic factors delivered by the neural progenitor cells could act retrogradely to modulate synaptic loss and thus maintain the firing properties of the lesioned cells. This is consistent with the actions of synaptotrophic factors, such as VEGF, which can alter the balance of inhibition to excitation.

\section{Materials and Methods}

Animals and surgical procedures. Experiments were performed on adult female cats weighing $2.0-2.5 \mathrm{~kg}$ obtained from authorized suppliers (Universidad de Córdoba, Córdoba, Spain). All procedures were in compliance with the guidelines of the European Union (2010/63/ EU) and Spanish legislation (R.D. 53/2013 BOE 34/11370-421), and were authorized by the ethics committee of Universidad de Sevilla. Five animals were prepared for electrophysiological recordings and received either an axotomy of the MLF $(n=1)$ or an axotomy plus the implantation of neural progenitor cells $(n=4)$. Additional recordings from six control animals (unpublished data; Pastor and Gonzalez-Forero, 2003) and two axotomized animals (de la Cruz et al., 2000) were also used.

Six additional animals were used solely for histology, as follows: four animals for confocal fluorescence microscopy of the abducens nucleus and the MLF, which received the axotomy alone $(n=2)$ or the axotomy plus the implant $(n=2)$; and two of them, axotomized and implanted, were used for ultrastructural analysis of the lesion site in the MLF. Animals used for the morphological study were processed after a survival time of 2 months postlesion. No attempt was made to follow the time course and evolution of the implant in this study.

Animals were prepared for chronic recordings as previously described (Davis-López de Carrizosa et al., 2009). Briefly, animals received an injection of atropine sulfate $(0.5 \mathrm{mg} / \mathrm{kg}$, i.m.) to reduce vagal reflexes and were then anesthetized with ketamine hydrochloride $(20 \mathrm{mg} / \mathrm{kg}$, i.m.) mixed with xylazine $(0.5 \mathrm{mg} / \mathrm{kg}$, i.m.). They were implanted intracranially with bipolar stimulating electrodes at the exit of the abducens nerve and in the MLF to antidromically activate abducens motoneurons and interneurons, respectively (Fig. 1A). Coils were implanted in the sclera of both eyes to record ocular movements, and a pedestal was constructed to
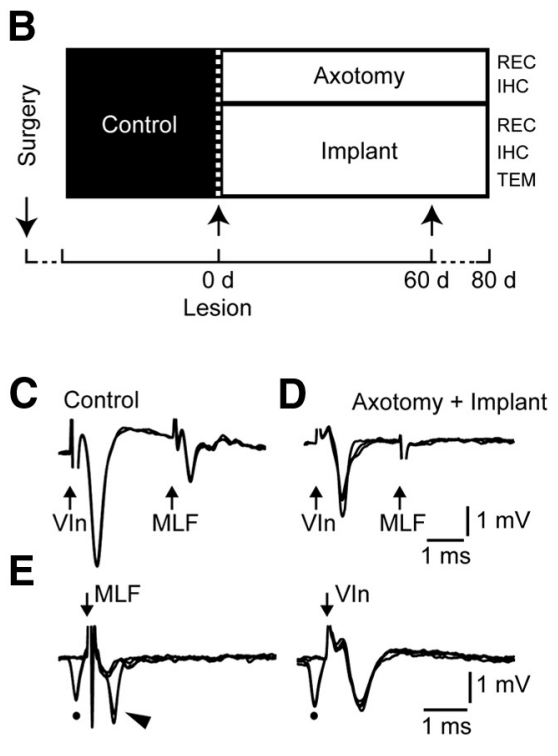

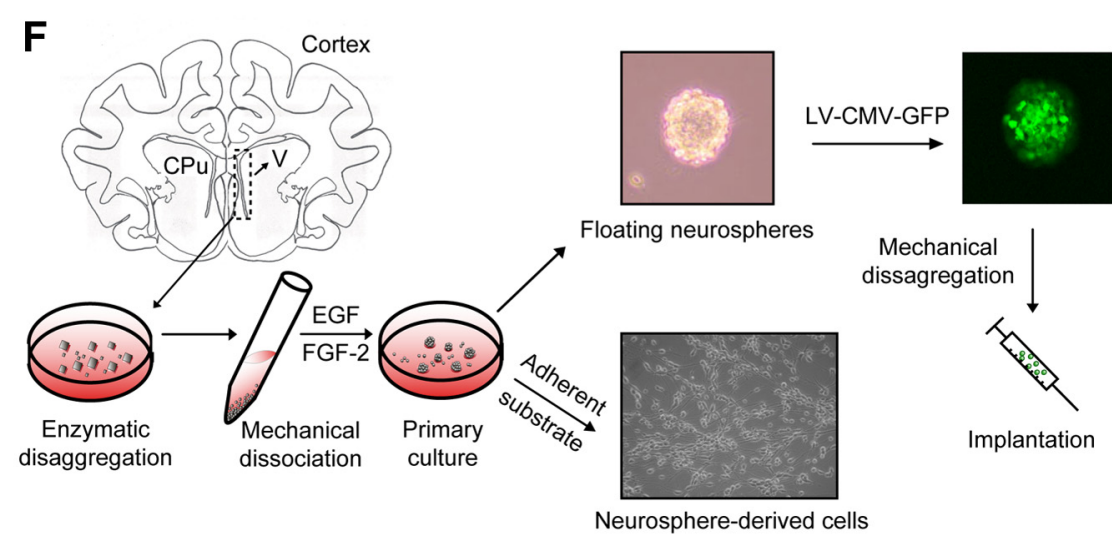

Figure 1. Experimental design and cellular identification. $A$, Diagram of connections of abducens (ABD) motoneurons and internuclear neurons (Int). Bipolar stimulating (St) electrodes were implanted in the VIn and in the MLF, respectively. The right MLF was sectioned (Ax) and implanted with neural progenitor cells (Imp). Recordings (Rec) were performed in the left ABD nucleus. $\boldsymbol{B}$ 列 corthodromic spike (dot) when the electrical shock was applied to the VIn. $\boldsymbol{F}$, The subventricular zones were ( sine adherent substrate, neurosphere-derived cells adhered to the dish and differentiated. Alternatively, neurospheres were transduced with lentiviral vectors containing a reporter gene for green fluorescent protein expressed under the control of a cytomegalovirus (CMV) promoter [lentiviral (LV)-CMV-GFP] and implanted in axotomized cats.

facilitate head-fixed extracellular recordings. Postoperative care was provided daily, as needed.

Extracellular recordings. Control recording sessions started $\sim 10 \mathrm{~d}$ after surgery (Fig. 1B). Experimental sessions started $4 \mathrm{~d}$ after lesioning, and lasted for $75 \mathrm{~d}$ in the axotomy group and $77 \mathrm{~d}$ in the implanted group. The animal was gently placed inside a fabric bag, wrapped with elastic bandages, and positioned in a recumbent posture within a Plexiglas box, which was in turn placed inside the magnetic field for eye movement recording (Fuchs and Robinson, 1966). Procedures for extracellular recordings followed those described before (Davis-López de Carrizosa et al., 2009). The cellular electrophysiological identification proceeded as follows: the (left) abducens nucleus was located by recording the antidromic field potential produced by electrical stimulation of the VIth nerve (VIn; Fig. 1C), in some cases aided by the antidromic field potential produced by the activation of abducens internuclear neurons after stim- 
ulation of the MLF (Fig. 1C; MLF). Control abducens internuclear neurons were identified by their antidromic activation from the MLF, a collision test between the orthodromic and antidromic action potentials, and a lack of antidromic activity following VIth nerve stimulation (Fig. $1 E, M L F)$. Axotomized abducens internuclear neurons were identified following the same criteria as previously described (de la Cruz et al., 2000): (1) the location within the limits of the antidromic field potential of the abducens nucleus induced following VIth nerve stimulation (Fig. $1 C$, VIn); (2) the failure of antidromic activation from the electrodes placed in the MLF and VIth nerve (Fig. 1D, MLF, E, VIn); and (3) the characteristic pattern of neuronal activity in relation to horizontal eye movements that will be described below.

Data storage and analysis. The horizontal and vertical eye positions (EPs) of both eyes and neuronal activity were digitally stored for off-line analysis (Power 1401, Cambridge Electronic Design). For data selection, computer programs written in Matlab 6.5 displayed instantaneous firing frequency and the positions of both eyes. Relationships between neuronal firing rate [FR; in spikes per second (sp/s)] and horizontal EP (in degrees) were obtained by linear regression analysis to calculate the slope (i.e., the neuronal sensitivity to eye position; $k$, in $\mathrm{sp} / \mathrm{s} /{ }^{\circ}$ ), the ordinate intercept $\left(F_{0}\right.$, in sp/s), and the abscissa intercept [the recruitment threshold $(\mathrm{Th})$, in degrees]. Firing rates during fixations were fitted to the equation $\mathrm{FR}=k \times \mathrm{EP}+F_{0}$. Relationships between neuronal firing and eye velocity $(\mathrm{EV})$ during saccades were obtained by linear regression analysis after subtraction of the position component $(k \times \mathrm{EP})$, which was calculated from the previously known sensitivity to eye position. Thus, the equation used was $\mathrm{FR}-k \times \mathrm{EP}=r \times \mathrm{EV}+F_{0}$, where $r$ (in sp/second per degree/second) is the neuronal sensitivity to EV (in degrees/second). For the separate calculation of the on and off components of $k$ and $r$, the criterion was to sort fixations or saccades discriminating those that moved the eye in the on or in the off direction (Delgado-Garcia et al., 1986a,b). It should be noted that fixations occurring after on-directed saccades that started and ended within the off hemifield were considered as on fixations, and vice versa. In the case of $k$-off and $r$-off, those fixations and saccades that silenced activity were excluded from the analysis. Due to the motor impairment of the eye ipsilateral to the MLF transection, we used the eye movement of the contralateral eye for computations.

Neural progenitor cell culture and viral transfection. To the best of our knowledge, this is the first report using neural progenitor cells obtained from the subventricular zone of newborn (3- to 5-d-old) cats. The material obtained from one kitten produced enough cells to implant two adult hosts. After decapitation and brain extraction, a thick slice containing the forebrain ventricles was placed in Leibovitz L-15 culture media (Invitrogen). The lateral walls of the lateral ventricles were dissected, chopped, and enzymatically dissociated with $2.5 \%$ trypsin for $15 \mathrm{~min}$ in DMEM mixed 1:1 with Ham's F-12 (DMEM/F-12; Invitrogen). After mechanical disaggregation with fire-polished Pasteur's pipettes, the material was centrifuged at $900 \mathrm{rpm}$, and the pellet was resuspended twice in DMEM/F-12 containing B-27 (Invitrogen), which was supplemented with $20 \mathrm{ng} / \mathrm{ml}$ epidermal growth factor (EGF; Invitrogen) and $10 \mathrm{ng} / \mathrm{ml}$ basic fibroblast growth factor (FGF-2; Millipore), and maintained with an atmosphere of $95 \% \mathrm{O}_{2}$ and $5 \% \mathrm{CO}_{2}$, at $37^{\circ} \mathrm{C}$. After 2-3 d, floating neurospheres were observed and then subcultured every $48-72 \mathrm{~h}$ until the moment of either transplantation or plating for in vitro differentiation (Fig. $1 F$ ). Before transplantation, neurospheres were prelabeled with either a fluorescent lipophilic tracer (PKH26; Sigma; GudiñoCabrera et al., 2000) or transfected overnight with a lentiviral vector containing a reporter gene for green fluorescent protein (GFP) expressed under the control of a cytomegalovirus promoter (titer, $10^{7} \mathrm{pfu} / \mathrm{ml}$ ) with a multiplicity of infection of 3 . The virus-containing culture medium was removed and replaced with fresh DMEM/F12 supplemented with B-27, EGF, and FGF-2. After 48-72 h of incubation, neurosphere-derived cells were already expressing GFP and ready to be implanted. Before the cell implantation, neurospheres were mechanically disaggregated to generate a cell suspension. The viral vector yielded nearly complete labeling of the transfected neurosphere-derived cells, and allowed us to study their fine details with fluorescence and electron microscopes after implantation. The phenotype of these cells was not affected by the lentiviral transfection.
Transection of the MLF and injection of neural progenitor cells. Abducens internuclear axons cross the midline at the level of the abducens nucleus and then course toward the oculomotor complex. The transection of the MLF was performed stereotaxically using a microblade, as previously described (de la Cruz et al., 2000). Briefly, animals received a unilateral lesion of the MLF with a microblade of $2 \mathrm{~mm}$ width aimed stereotaxically toward the right MLF at the pontomesencephalic level (Pastor et al., 2000). Histology revealed lesions $0.5-1 \mathrm{~mm}$ caudal to the trochlear nucleus, that were confined to depths of $2-2.5 \mathrm{~mm}$ beneath the ventricular surface (Fig. 1A; see also Fig. 3A). Immediately after lesioning the MLF, the neural progenitor cells were injected through the tip (50 $\mu \mathrm{m}$ ) of a micropipette connected to a Hamilton syringe using the same coordinates as for the lesion of the right MLF. Once at the calculated MLF depth, an ascending tract of $1 \mathrm{~mm}$ was made as $1 \mu \mathrm{l}$ of the cell suspension containing $\sim 50,000$ cells was slowly ejected over a period of $1 \mathrm{~min}$. The syringe was left in place for another minute and then gently removed.

Anterograde tracing. In the last recording session, two implanted animals received an electrophoretic injection of biotinylated dextran amine (BDA; Invitrogen) to reveal the fate of the severed axons of abducens internuclear neurons. Micropipettes with a tip diameter of $20-25 \mu \mathrm{m}$ were filled with $3 \% \mathrm{BDA}$ in Tris- $\mathrm{HCl}$ buffer $(0.05 \mathrm{~m}), \mathrm{pH}$ 7.4. Cathodal current pulses of $7 \mu \mathrm{A}$ intensity (50\% duty cycle) were applied for $20 \mathrm{~min}$ at three different locations within the abducens nucleus contralateral to the severed MLF. After $7 \mathrm{~d}$, animals were perfused transcardially under deep anesthesia (sodium pentobarbital, $50 \mathrm{mg} / \mathrm{kg}$, i.p.). The fixative was $4 \%$ paraformaldehyde in $0.1 \mathrm{~m}$ sodium phosphate buffer, $\mathrm{pH} 7.4$. Brainstem parasagittal sections of $50 \mu \mathrm{m}$ thickness were cut on a vibratome and collected in PBS, $\mathrm{pH}$ 7.4. BDA was revealed following overnight incubation in streptavidin-TRITC (1:500; Jackson ImmunoResearch) prepared in PBS with $0.1 \%$ Triton X-100 (PBS-T). After rinsing, sections were mounted on slides and prepared for immunofluorescence microscopy.

Immunohistochemical procedures for fluorescent confocal microscopy. Animals used for the immunohistochemical study were processed 2 months after the lesion (Fig. 1B). Coronal sections were cut on a Vibratome to a thickness of $50 \mu \mathrm{m}$. Sections containing the abducens nucleus were washed in PBS-T and, after blocking unspecific sites with $10 \%$ normal donkey serum in PBS-T for $1 \mathrm{~h}$, were left overnight at room temperature in the primary antibody solution prepared in PBS-T with $5 \%$ normal donkey serum and $0.05 \%$ sodium azide. Double, occasionally triple, immunofluorescence labeling was undertaken for the following: calretinin (a marker for abducens internuclear neurons; de la Cruz et al., 1998), along with either synaptophysin (a general synaptic marker), vesicular GABA and glycine amino acid transporter (VGAT) for inhibitory synaptic boutons (González-Forero et al., 2004), or glial fibrillary acidic protein (GFAP) to identify astrocytes. The primary antibodies used were the following: calretinin [goat polyclonal antibody (pAb), 1:500; Swant], synaptophysin (mouse mAb, 1:2000; Millipore), VGAT (rabbit pAb, 1:500; Millipore), and GFAP (rabbit pAb, 1:500; DAKO). After washing, sections were incubated in a solution containing the appropriate fluorescently tagged secondary antibody for $2 \mathrm{~h}$ (prepared in PBS-T, 1:50-1:100; Jackson ImmunoResearch). After rinsing, sections were mounted on glass slides and coverslipped with Vectashield (Vector Laboratories). In addition, parasagittal sections through the lesion and implant site in the MLF were processed for GFAP, synaptophysin (as described above), or doublecortin (a marker of immature neurons) using as a primary antibody a goat anti-doublecortin antibody (1:100; sc-8066, Santa Cruz Biotechnology), followed by appropriate secondary antibodies.

A confocal microscope (TCS SP2, Leica) was used to capture $1024 \times$ 1024 pixel images, and analysis was performed with Image (NIH). Grayscales were adjusted to maximize their dynamic range. Neurons were scanned in one to four different focal planes containing the nucleus along the $z$-axis $(63 \times$ objective). The somatic coverage was measured and presented as the percentage ratio between the surface occupied by synaptophysin-immunoreactive boutons, VGAT-immunopositive terminals, or GFAP-immunostained profiles, and the perimeter of the calretinin-immunopositive somata of internuclear neurons (Pastor et al., 1997). The mean gray value in the neuropil stained for synaptophysin, VGAT, and GFAP was also measured using square boxes of 80 pixels per 
side $(25.8 \mu \mathrm{m})$, sampled through the neuropil of images captured with the $40 \times$ objective.

For VEGF immunocytochemistry of the implanted cells, the primary antibody used was a rabbit anti-VEGF (1:50; sc-507, Santa Cruz Biotechnology). For Flk1, the VEGF receptor visualized in abducens internuclear neurons, we used a mouse anti-Flk1 (1:1000; sc-6251, Santa Cruz Biotechnology), an antibody that selectively labels neurons (Ruiz de Almodovar et al., 2011), followed by calretinin immunolabeling (as described above) for the specific identification of abducens internuclear neurons.

Immunocytochemistry in neurosphere cultures. To analyze the ability of neurosphere-derived cells to generate the different neural lineages, they were seeded on poly-lysine-treated coverslips in DMEM/F-12 with $1 \%$ fetal calf serum for $4 \mathrm{~h}$ to facilitate adhesion and then in DMEM/F-12 with B-27, EGF, and FGF-2 added. After $48 \mathrm{~h}$ in the incubator, cells were fixed with $4 \%$ paraformaldehyde in PBS $0.1 \mathrm{~m}$ for $10 \mathrm{~min}$. In other experiments, neurospheres were fixed immediately after the initial $4 \mathrm{~h}$ of adhesion to the substrate. Immunocytochemical processing included the following various double combinations of the following markers: $\beta$ III-tubulin, a constituent protein of microtubules used to selectively discriminate neurons from glia (mouse mAb, 1:500; Promega); doublecortin, a microtubule-associated protein expressed almost exclusively by immature neurons (goat pAb, 1:500; Santa Cruz Biotechnology); GFAP, a marker of astrocytes (rabbit pAb, 1:500; DAKO); and NG-2 chondroitin sulfate proteoglycan, a marker of oligodendrocyte precursors (rabbit pAb, 1:400, Millipore). Secondary antibodies were all raised in donkey and tagged to different cyanine dyes as needed for color separation of the immunoreactions (1:200; Jackson ImmunoResearch). Incubation times were $2 \mathrm{~h}$ and $30 \mathrm{~min}$ for primary and secondary antibodies, respectively. Counterstaining with $4^{\prime}, 6^{\prime}$-diamidino-2phenylindole dihydrochloride (DAPI; $0.1 \mu \mathrm{g} / \mathrm{ml}, 10 \mathrm{~min}$ incubation) was always performed after the immunocytochemical procedure. Fluorescence signals were detected and analyzed with a BX61 Olympus epifluorescence microscope.

In situ hybridization for detection of trophic factor mRNAs. In situ hybridization with oligonucleotide probes was performed in neonatal cat subventricular zone-derived neurospheres, as previously described (Morcuende et al., 2011), following the protocol of Wisden and Morris (2002). Oligonucleotide probes complementary to parts of mRNA encoding BDNF, NGF, NT-3, or VEGF were synthesized (Sigma-Genosys) and radiolabeled with $\alpha^{-}{ }^{35}$ S-dATP (GE Healthcare) at the $3^{\prime}$ end using terminal deoxyribonucleotidyl transferase (Promega). The specific activities of labeled probes ranged from 200,000 to $300,000 \mathrm{cpm} / \mu \mathrm{l}$. The following antisense DNA oligonucleotides were used: BDNF mRNA, $5^{\prime}$ CCA TGG GAT TAC ACT TGG TCT CGT AGA AAT ATT GCT TCA GTT GGC-3' (accession number NM_012513, bases 1190-1234; Maisonpierre et al., 1991); NGF mRNA, 5'-TGC GGG CTC TGC GGA GGG CTG TGT CAA GGG AAT GCT GAA GTT TAG T-3' (accession number M36589, bases 401-446; Whittemore et al., 1988); NT-3 mRNA, 5' -TCA ATC CCC CTG CAA CCG TTT TTG ACT GGC CTG GCT TCT TTA CA-3' (accession number M34643, bases 658-701; Ernfors et al., 1990); VEGF mRNA: 5' -CAC ATC TGC AAG TAC GTT CGT TTA ACT CAA GCT GCC TCG CCT TGC-3' (accession number NM_001110336, bases 581-625; Conn et al., 1990). Although the nucleotide sequences for the cat neurotrophins or VEGF are not completely known, a GenBank search revealed that the sequences used here are highly conserved in rat, mouse, and human (Lein et al., 2000).

Neurospheres seeded on poly-lysine-coated glass slides in DMEM/ F-12 medium with $1 \%$ fetal calf serum for $4 \mathrm{~h}$ were fixed for $5 \mathrm{~min}$ in $4 \%$ paraformaldehyde, progressively dehydrated, and stored in 95\% ethanol. Slides that underwent in situ hybridization were air dried for $1-2 \mathrm{~h}$. Cells were visualized and analyzed by bright-field microscopy (Axiophot microscope, Zeiss).

Electron microscopy processing. Two months postlesioning, animals were prepared for electron microscopy analysis (Fig. 1B). The intracardial perfusion consisted of a brief wash with physiological saline solution followed by a phosphate-buffered fixative containing $4 \%$ paraformaldehyde and $0.3 \%$ glutaraldehyde. The brainstem was removed and sectioned parasagittally at $100 \mu \mathrm{m}$ by use of a vibratome. For the pre-embedding processing of GFP, sections selected for their green fluorescence due to this marker (in neural progenitor cells, see above) were frozen and thawed three times using the vapors of liquid nitrogen for permeabilization purposes, and then a standard immunocytochemical technique was applied using overnight incubation in a primary antiGFP antibody raised in mouse (1:2000; Millipore) followed by a $2 \mathrm{~h}$ incubation in a biotinylated anti-mouse antibody raised in goat (1:250; Vector Laboratories). Biotin was revealed according to the avidin-biotin-peroxidase complex method using $3,3^{\prime}$-diaminobenzidine tetrahydrochloride as the chromogen. Sections were postfixed in $1 \%$ osmium tetroxide for $2 \mathrm{~h}$ and stained en bloc with uranyl acetate, dehydrated and flat embedded in Durcupan ACM resin (Fluka). Ultrathin sections were examined with a transmission electron microscope (CM10, Philips).

The procedure for postembedding GFAP immunostaining of ultrathin sections was adapted from our previous protocol (de la Cruz et al., 1992). Ultrathin sections were incubated for $2 \mathrm{~h}$ in a rabbit anti-GFAP primary antibody (1:500; DAKO). The secondary antibody was a goat anti-rabbit IgG conjugated to gold colloidal particles of $10 \mathrm{~nm}$ (1:30, for $2 \mathrm{~h}$; Sigma). A silver enhancement method for gold particles was applied before counterstaining with lead citrate and uranyl acetate (Danscher and Zimmer, 1978).

Statistics. Comparisons between groups were performed using one- or two-way ANOVA followed by post hoc pairwise multiple comparisons using the Holm-Sidak method at an overall significance level of 0.05 with the program SigmaPlot 11 (Systat Software GmbH.). Values were expressed as the mean $\pm \mathrm{SD}$, unless otherwise specified.

\section{Results \\ Multipotentiality of neural progenitor cells and graft-host interaction}

This study shows that neural progenitor cells isolated from the postnatal cat subventricular zone can be amplified in vitro, are multipotent, and retain their ability to synthesize neurotrophic factors. Neural progenitor cells cultured as floating neurospheres differentiated into several lineages when subcultured on an adherent substrate. Thus, after $48 \mathrm{~h}$ in vitro, individual populations of adhered cells expressed the astrocytic marker GFAP (Fig. 2A), the neuronal marker $\beta$ III-tubulin (Fig. $2 B$ ), doublecortin, as a marker of immature neurons, and/or NG-2 for oligodendrocyte precursors (data not shown). Even after only $4 \mathrm{~h}$ of adhesion to the substrate, some neurosphere-derived cells began to differentiate (Fig. 2C, labeled for NG-2). We also demonstrated by in situ hybridization that neurosphere-derived cells expressed the $\mathrm{mR}$ NAs of the trophic factors NGF, NT-3, and VEGF (Fig. 2D-F), but did not express BDNF mRNA (data not shown).

When implanted into the lesioned MLF (Fig. $3 A$ ), disaggregated neurospheres also yielded diverse phenotypes in vivo. The implant appeared 2 months after grafting as a mass of cells with rounded cell bodies that accumulated along the lesion tract (Fig. $3 B-D)$. No attempt was made in this study to characterize the time course of the host-graft interaction. All morphological data presented here were obtained at 2 months postimplantation, which corresponded to the period in which we recorded the majority of cells. The immunoreaction against GFAP demonstrated the borders of the lesion (Fig. 3B). The implanted cells extended long, fine processes for distances of up to $500 \mu \mathrm{m}$ (Fig. 3C,D). We found that $10.4 \%$ of the GFP-positive cells were immunoreactive for GFAP (Fig. 3E-G). Approximately $6 \%$ of the implanted cells were doublecortin immunoreactive (Fig. $3 H-J$ ). The neuronal marker $\beta$ III-tubulin was detected in $5.5 \%$ of the implanted cells. A lower proportion of cells (2.6\%) showed NG-2 immunolabeling, a marker for oligodendrocytic precursors (not illustrated). These results indicated moderately low levels of neural progenitor cell differentiation The host-graft interaction was studied by means of anterograde BDA tracing from the contralateral abducens nucleus. The axons of lesioned abducens internuclear neu- 

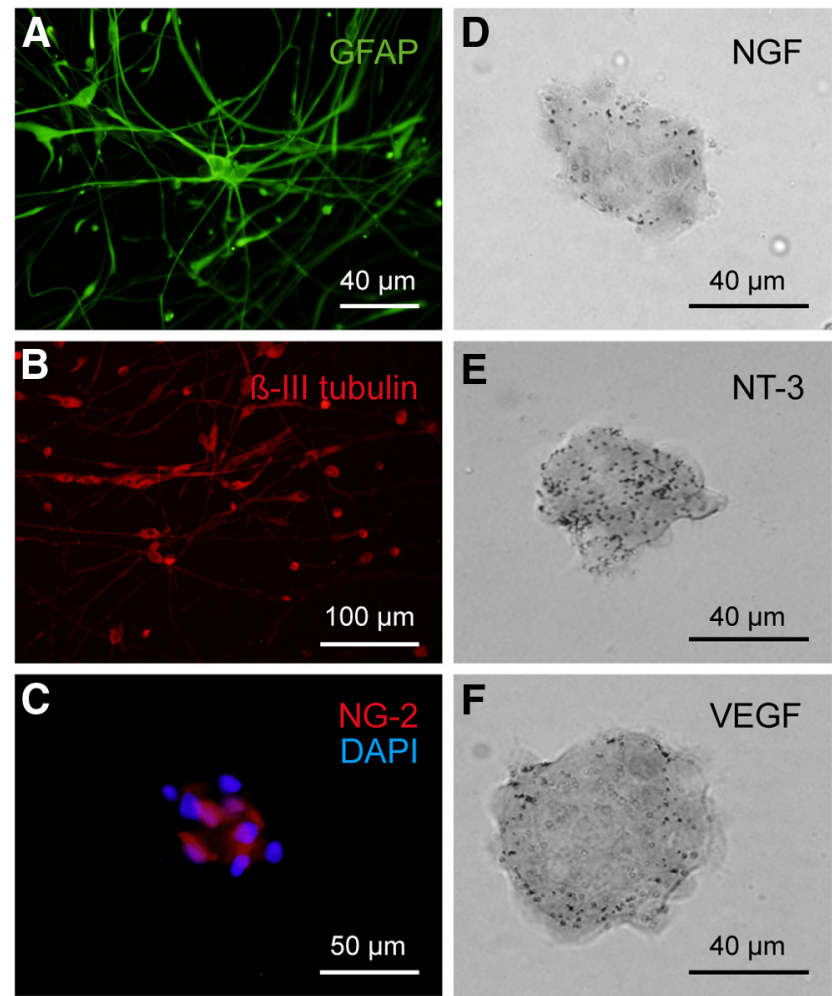

Figure 2. Phenotypic characterization of neural progenitor cells in vitro. $\boldsymbol{A}-\boldsymbol{C}$, Cells derived from neurospheres and cultured on a poly-D-lysine adherent substrate expressed markers of astrocytes (GFAP, green, $\boldsymbol{A}$ ), neurons ( $\beta$-III tubulin, red, $\boldsymbol{B}$ ), and oligodendrocyte precursors (NG-2, $\mathbf{C}$. In $\boldsymbol{C}$, the NG-2 immunofluoresence (in red) is illustrated for a neurosphere and is accompanied by counterstaining with DAPI (in blue) to visualize the cell nuclei. $\boldsymbol{D}-\boldsymbol{F}$, In situ hybridization of $m R N A$ in neurospheres derived from postnatal cats showing the expression of $\operatorname{NGF}(\boldsymbol{D}), \mathrm{NT}-3(\boldsymbol{E})$, and VEGF $(\boldsymbol{F})$.

rons showed close relationships with the implanted cells (Fig. $3 K)$. In some instances, close appositions, reminiscent of synaptic contacts, were observed between axonal endings (labeled by synaptophysin) and implanted GFP-positive cells (Fig. $3 L$ ).

We evaluated the presence of VEGF in the implanted neural progenitor cells. For this purpose, we performed VEGF immunostaining in parasagittal brainstem sections taken through the lesion and implant site. Our data revealed that $\sim 68 \%$ of the GFP-positive implanted cells were also VEGF immunoreactive (Fig. 3M). Moreover, we also analyzed, by double immunofluorescence, whether abducens internuclear neurons were endowed with the VEGF receptor Flk1. In the three experimental situations (control, axotomy, and postimplant), we found that all the calretinin-immunopositive cells in the abducens nucleus expressed the receptor Flk1 (Fig. 3N).

\section{Neural progenitor cell implantation prevents axotomy-} induced firing alterations in abducens internuclear neurons Abducens neurons display tonic and phasic firing patterns during spontaneous horizontal eye fixations and saccades, respectively (Delgado-Garcia et al., 1986b). Control abducens internuclear neurons showed a tonic regular discharge that correlated with eye position during eye fixations (Fig. $4 A$ ). Tonic firing rate increased proportional to the amplitude of eye rotations directed toward the side of recording, called the on-direction. By the same token, firing rate decreased proportional to eye positions aimed at the off-direction with respect to the recording site (Fig. 4A). Therefore, the slope of the linear regression analysis of firing rate versus the eye position allowed the extraction of the neuronal eye position sensitivity ( $k$; measured in sp/seconds/degree; Fig. 4D, F, black lines and dots). The abscissa intercept of the firing rate-toeye position plot is considered the eye position threshold at which the unit is recruited into activity (Fig. $4 D$, Th). The firing rate of the internuclear neurons was also correlated with eye velocity during saccades; thus, high-frequency bursts and pauses appeared during on-directed and off-directed saccades, respectively (Fig. 4A). The slope of the linear regression analysis between firing rate and eye velocity during saccades was considered the sensitivity to eye velocity, namely, $r$ (Fig. $4 E, G$, black lines and dots).

The firing pattern of abducens internuclear neurons, but not that of abducens motoneurons, changed as soon as $4 \mathrm{~d}$ after MLF lesioning. This pattern remained altered for $>2$ months (de la Cruz et al., 2000; present data). Axotomized internuclear neurons had a drastic reduction in firing rate that disrupted the firing pattern (Fig. 4B). They showed a decline in modulation in relation to both eye position and velocity (Fig. $4 D-G$, red lines and dots). These alterations yielded lower $k$ and threshold values $(p<$ 0.05 ) during fixations compared with controls (Fig. $4 D, F$ ), as well as lower $r$ values during saccades (Fig. $4 E, G$ ). Interestingly, a fundamental finding was that the implantation of neural progenitor cells in the MLF immediately after the lesioning prevented lesion-induced decay in both the $k$ and $r$ values (Fig. $4 D-G$, blue line and dots), and also maintained the normal firing pattern of internuclear neurons (Fig. 4C).

Compared with control cells $(n=68)$, axotomy alone caused a reduction in both eye position and eye velocity sensitivity shortly after the lesioning ( $4 \mathrm{~d})$, and these values remained impaired throughout the entire experimental course. This indicated the absence of spontaneous recovery in the axotomy condition (Fig. $5 A, B$, red dots; $n=57$ ). The average population data demonstrated a near halving of both eye position and eye velocity sensitivities (Fig. $5 C, D$, asterisks; $p<0.05$ ), and a significant reduction in threshold (data not shown) as a consequence of the axotomy. Linear regression analysis of $k$ or $r$ values versus the recorded day showed no change in these parameters over time $(p>0.05)$ in the axotomy and postimplant groups. The implantation of neural progenitor cells maintained $k$ values similar to control values from the onset of the experiment (Fig. $5 A$, blue dots; $n=97$ ). The average $k$ value after the implant was significantly different from the axotomy value, and similar to control values (Fig. $5 C ; p<0.05$ ). The same finding was also obtained regarding threshold (data not shown). With respect to eye velocity sensitivity, the implantation of neural progenitor cells produced only a partial re-establishment of this parameter $(r)$. Thus, the mean $r$ value in the postimplant group was significantly different from both the axotomy alone and control data (Fig. $5 D$, dot and asterisk; $p<0.05$ ).

\section{Alterations in the inhibition-to-excitation balance}

To determine whether excitatory versus inhibitory firing signals were differentially recovered after neural progenitor cell implants, we independently measured the on and the off components of both eye position and velocity sensitivities as separate indexes of the excitation and the inhibition received by abducens neurons (Delgado-Garcia et al., 1986a,b). The $k$-on component was measured as the slope of the regression line between firing rate and fixations that resulted after on-directed saccades. The opposite procedure was used to measure $k$-off components; that is, fixations attained after off-directed saccades were used, as illustrated for an internuclear neuron of each experimental group 
(Fig. 5E). Similarly, saccades were sorted out into on-directed and off-directed saccades, and correlations were made separately (Fig. $5 F$ ). Axotomy reduced both the $k$-on and $k$-off values, and the implant elevated both parameters to normal levels when compared with the respective $k$-on or $k$-off values of the control group (Fig. $5 G ; p<0.05)$. Therefore, with respect to the tonic signal, both the excitatory and the inhibitory components appeared similar to control values, revealing that the on/off synaptic drive during fixations (tonic firing) was balanced like that seen under the control situation. With respect to the phasic (saccadic) signal, axotomy also led to a reduction in both $r$-on and $r$-off parameters, compared with control $r$-on or $r$-off values, respectively (Fig. $5 H$ ). In contrast, $r$-on and $r$-off had different behaviors after neural progenitor cell implants. The $r$-off obtained in the postimplant group was similar to the control $r$-off value. However, the r-on component lay between that of the axotomy and the control $r$-on values (Fig. $5 H$; $p<0.05$ ). These data indicated that whereas the inhibitory signal for off-directed saccades was completely re-established, the excitatory drive for on-directed saccades was only partially restored. These results point to an imbalance of the inhibitory-to-excitatory ratio caused by increased inhibition or a lack of excitation compared with controls.

\section{Neural progenitor cell implants prevent synaptic stripping on abducens internuclear neurons}

We sought to find a structural correlate of the functional alterations described above by investigating changes in the synaptology of abducens internuclear neurons. The somatic surface coverage of abducens internuclear neurons by synaptic boutons and astrocytic processes was measured by means of immunocytochemistry against synaptophysin and GFAP, respectively. To determine the ratio of inhibition to excitation, we measured the synaptic coverage of inhibitory boutons by using immunostaining against VGAT. In control abducens internuclear neurons, $60.5 \pm 8.0 \%$ of the somatic perimeter was surrounded by synaptophysin-

immunoreactive boutons (Fig. $6 A, D ; n=46$ cells), and $7.4 \pm$ $4.3 \%$ was covered by astrocytic processes (Fig. $6 I, L$, Con; $n=$ $65)$. The percentage of the somatic perimeter covered by inhibitory boutons (i.e., VGAT-immunoreactive boutons) was $34.6 \pm$ $7.1 \%$ in controls (Fig. $6 E, H$, Con; $n=47$ ). Axotomy significantly reduced the percentage of the somatic perimeter covered by synaptic boutons, which were identified as synaptophysin immunopositive, to $35.2 \pm 7.8 \%$ (Fig. $6 B, D$, Ax; $n=30 ; p<0.05$ ). Axotomized neurons also showed a significant decrease in their
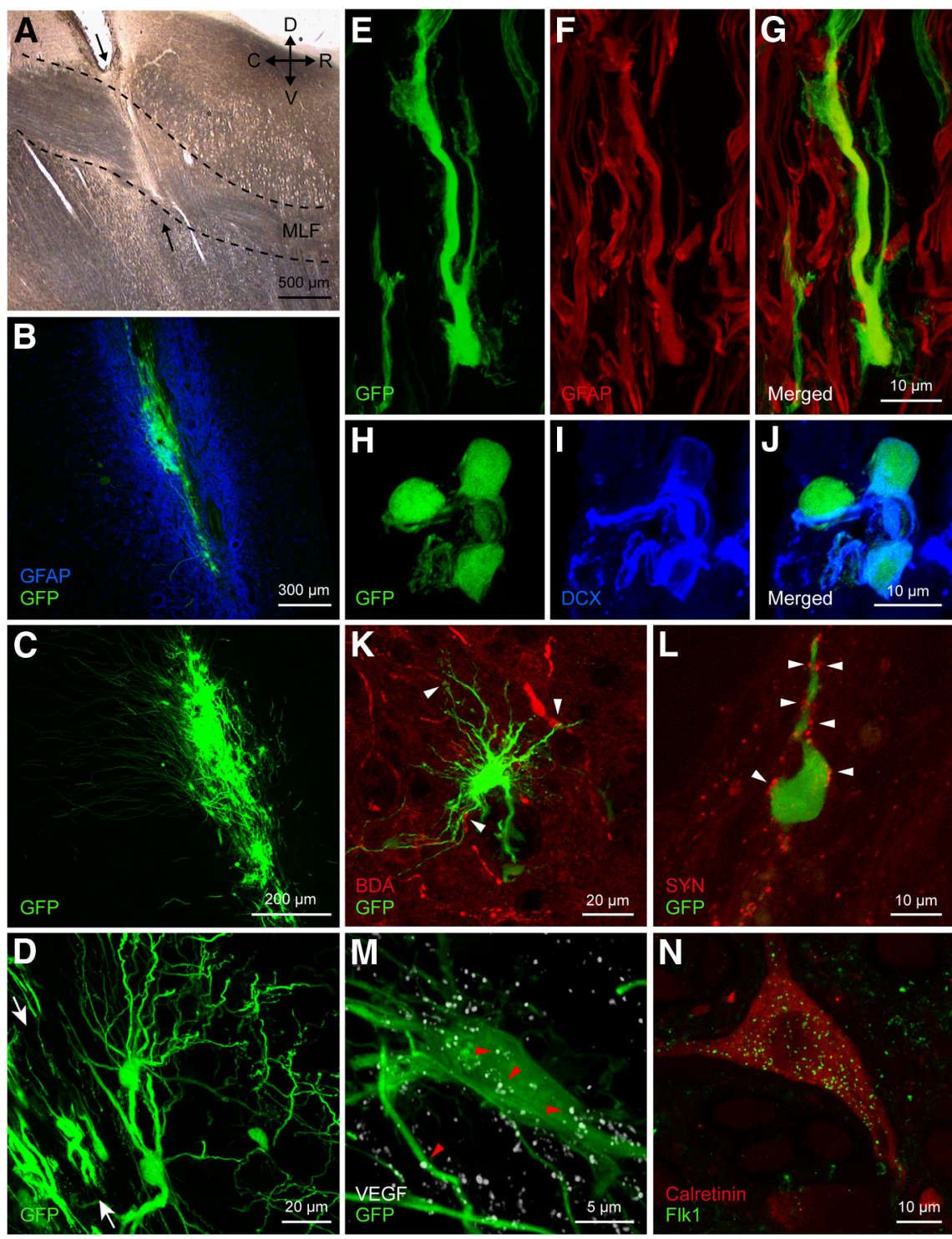

Figure 3. Implant-host interaction. $\boldsymbol{A}$, Parasagittal section through the brainstem showing the transection (arrows) of the MLF (delimited by dashed lines). D, Dorsal; $C$, caudal; R, rostral; V, ventral. $\boldsymbol{B}-\boldsymbol{D}$, Confocal microscopic images of the implanted neural progenitor cells expressing GFP in the lesioned MLF. Note the presence of an intense astrocytic reaction around the lesion, as shown by GFAP immunostaining ( $\boldsymbol{B}$; blue), and the fine processes of the implanted cells ( $\boldsymbol{C}$ and $\boldsymbol{D}$ ). Arrows in $\boldsymbol{D}$ indicate the location of the lesion and implant tract. $\boldsymbol{E}-\mathbf{G}$, Some implanted, GFP-positive, neural progenitor cells differentiated into astrocytes (GFAP, red, $\boldsymbol{F}$ ). $\boldsymbol{H}-\boldsymbol{J}$, Implanted cells could also differentiate into neurons, as demonstrated by doublecortin (DCX) immunoreactivity (blue), a marker of immature neurons. $\boldsymbol{K}$, Example of the intimate association (arrowheads) between abducens internuclear axons (labeled anterogradely with BDA, in red) and an implanted neural progenitor cell (green). The image corresponds to a stack of 14 focal planes of $2 \mu \mathrm{m}$ thickness. $L$, Synaptic boutons [identified as synaptophysin immunoreactive (SYN) in red) in close apposition (arrowheads) to the cell body and process of another identified implanted cell. $\boldsymbol{M}$, Presence of VEGF in implanted neural progenitor cells. Note a GFP-positive implanted cell (in green) that was also VEGF immunoreactive (in white; arrowheads point to some immunoreactive dots). $\boldsymbol{N}$, Example of an abducens internuclear neuron from an implanted animal, identified as calretinin immunopositive (in red), showing also immunostaining for the VEGF receptor Flk1 (in green). Images in $\boldsymbol{M}$ and $\boldsymbol{N}$ correspond to a stack of 13 and 7 focal planes of $0.8 \mu \mathrm{m}$ thickness, respectively.

somatic coverage by boutons of an inhibitory nature, identified by their VGAT immunoreactivity, with respect to control (Fig. $6 F, H, \mathrm{Ax} ; n=30 ; p<0.05)$. On the other hand, astrocytic processes proliferated to cover up to $12.3 \pm 7.2 \%$ of the cell surface (Fig. $6 \mathrm{~J}, L, \mathrm{Ax} ; n=42 ; p<0.05$ ). The implantation of neural progenitor cells did not totally prevent the drop in synaptophysin-immunoreactive boutons covering axotomized internuclear neurons, as the extent of coverage was intermediate between the control and the axotomized states (Fig. 6C,D, Imp; 


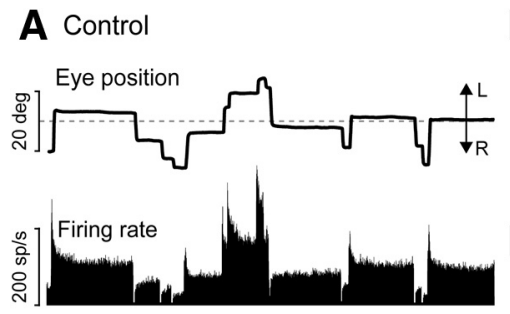

B Axotomy
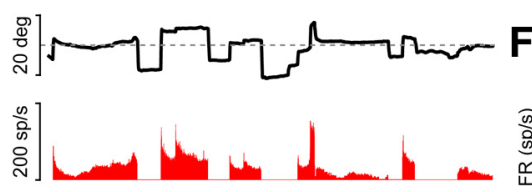

C Post-implant
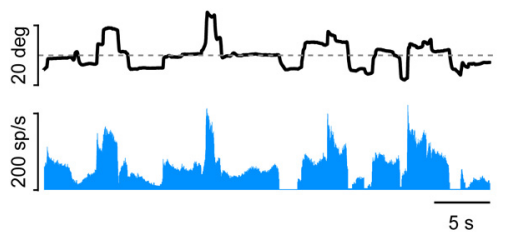

D

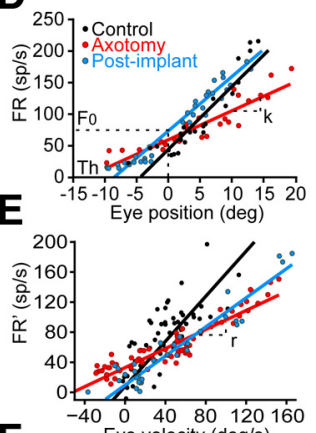

$\mathbf{F}$ Eye velocity (deg/s)
E $40 \quad 801201$

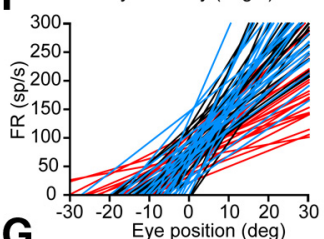

G

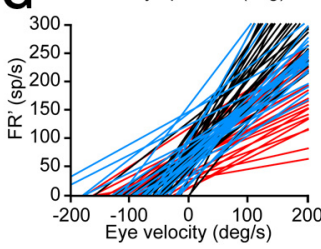

Figure 4. Effects of axotomy followed by a subventricular zone-derived neural progenitor implant on the firing pattern of abducens internuclear neurons. $A$, Firing rate (measured in spikes/s) of a control neuron during spontaneous eye movements [movements toward the left $(\mathrm{L})$ and right $(\mathrm{R})$ sides, respectively; deg, degrees]. $\boldsymbol{B}$, Firing rate of an internuclear neuron $14 \mathrm{~d}$ after axotomy. Note that both tonic and phasic components of the firing pattern are reduced. $C$, Example of an abducens internuclear neuron recorded $14 \mathrm{~d}$ after the axotomy and implant, illustrating the presence of a firing pattern that resembled the control situation. $\boldsymbol{D}$, Linear regression analysis between FR (spikes/s) and EP (degrees) for control (black), axotomized (14 $d$, red), and postimplant ( $15 \mathrm{~d}$, blue) abducens internuclear neurons. The slope of the regression line $(k)$ represents the neuronal eye position sensitivity, and $F_{0}$ is the firing rate at $0^{\circ}$. The recruitment Th is also indicated. $E$, Linear regression analysis between firing rate after subtracting the eye position component (FR'; in spikes/second) and eye velocity (in degrees/second) for a control (black), axotomized ( $75 \mathrm{~d}$, red), or postimplant ( $47 \mathrm{~d}$, blue) abducens internuclear neuron. The slope of the regression line represents the neuronal eye velocity sensitivity $(r) . \boldsymbol{F}$, Rate-position plots illustrating the sensitivity to eye position in control (black), axotomized (red), and postimplant (blue) abducens internuclear neurons ( 25 cells per group). G, Ratevelocity plots illustrating the sensitivity to eye velocity in control (black), axotomized (red), and postimplant (blue) abducens internuclear neurons for the same set of cells, as in $\boldsymbol{F}$.

$n=51)$. However, the VGAT coverage was maintained at values similar to control levels (33.8 $\pm 7.7 \%$; Fig. $6 G, H$, Imp; $n=35)$, indicating that the cell implantation prevented the loss of inhibitory inputs induced by the axotomy. This is in agreement with the neurophysiological findings. The implant also prevented the increase in perisomatic GFAP induced by axotomy, as this value was similar to that of controls and was different from axotomy values (Fig. $6 K, L, \operatorname{Imp} ; n=70 ; p<0.05$ with respect to axotomy).

Optical density measurements of the coverage of synaptophysin, VGAT, and GFAP obtained from the neuropil of the abducens nucleus showed changes similar to those mentioned for the somata, except that the synaptophysin coverage was similar to that of controls in the implanted group (not illustrated).

\section{Ultrastructural evidence of graft-host interaction}

Neural progenitor cells were easily identified within and around the limits of the lesion by their GFP immunoreactivity (Fig. 7A, asterisk). Frequently, surrounding each GFP-positive cell body,
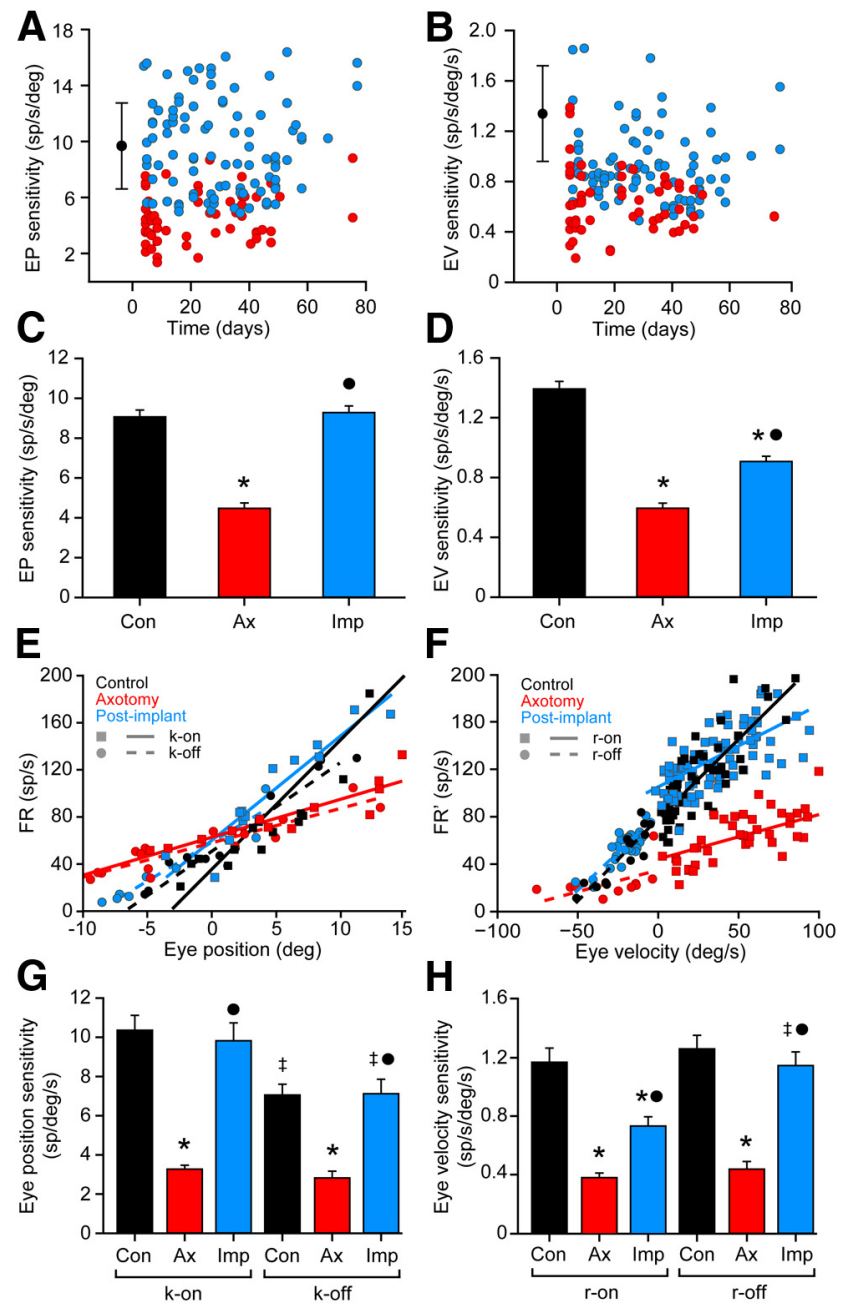

Figure 5. Analysis of the firing rate during spontaneous eye movements. A, Scatterplot of $k$ values for axotomized (red) and postimplant (blue) abducens internuclear neurons represented versus time (days after the axotomy/implant). Control data are illustrated as a black dot (mean) with error bars (SD). $\boldsymbol{B}$, Same as $\boldsymbol{A}$, but for eye velocity sensitivity $(r) . \boldsymbol{C}, \boldsymbol{D}$, Bar charts showing the mean \pm SEM values of eye position sensitivity $(k ; C)$ and eye velocity sensitivity $(r ; D)$ obtained from neurons of the three experimental conditions: control $(n=68)$, axotomy $(n=57)$, and postimplant $(n=97)$. Significant differences with respect to control and axotomy groups are indicated by * and , respectively ( $p<0.05$; ANOVA test, Holm-Sidak method for multiple comparisons). $\boldsymbol{E}$, Regression lines of $F R$ versus eye position sorting those fixations attained after on-directed saccades (solid lines; $k$-on) from those after off-directed saccades (dashed lines; $k$-off) for an internuclear neuron of each group. $\boldsymbol{F}$, Regression lines obtained after plotting the firing rate [minus the eye position component $\left(F R^{\prime}\right)$ ] versus the eye velocity during on-directed (solid lines; $r$-on) or off-directed saccades (dashed lines; $r$-off) for an internuclear neuron of each group. $\boldsymbol{G}, \boldsymbol{H}$, Bar charts showing the on/off values (mean \pm SEM) of eye position $(\boldsymbol{G})$ and velocity $(\boldsymbol{H})$ sensitivity, for 20 cells from each experimental population. Significant differences with respect to the control and axotomy groups for each parameter are shown by * and 0 , respectively, while $\ddagger$ represents significant differences between the on and off parameters within the same group ( $p<0.05$; two-way ANOVA test, Holm-Sidak method for multiple comparisons).

there was a field of smaller labeled elements interacting in a variety of ways with other, nonlabeled, elements at the lesion site (Fig. 7A, arrows). Astrocytes were identified by the presence of postembedding Immunogold GFAP labeling over the bundles of intermediate filaments (Fig. $7 B$, arrows, inset). Close appositions of implanted cell profiles with astrocytic elements were common (Fig. 7C, framed region), and, sometimes, extensive appositions to the cell membranes of microglial-like cells were observed (Fig. 7C,D). Within the MLF, immediately caudal to the lesion site, it was possible to find close relations between 
implanted cells and axonal elements. Axons lay in close proximity to GFP-labeled elements (Fig. 7E) that presumably were the result of long, fine extensions of the implanted cells observed with a light microscope. In some instances, it was possible to identify a postsynaptic density on the membrane of an implanted cell. Even in cases where the darkened cytoplasm from the GFP immunolabeling precluded observing postsynaptic densities, these terminal associations were considered to be indicative of a synaptic contact due to the clustering of synaptic vesicles in the presynaptic element (Fig. $7 F$ ). In all cases, synaptic vesicles were of the spherical type, like those of abducens internuclear neuron terminals contacting their natural or even novel targets (de la Cruz et al., 2002). On the other hand, we also observed a few enlarged axonal endings that resembled the terminal clubs previously described in axotomized abducens internuclear neurons. These lacked any postsynaptic elements (data not shown; see Pastor et al., 2000).

\section{Discussion}

In the present work, we have shown that neural progenitor cells derived from the postnatal cat subventricular zone interact with the host lesioned CNS after grafting, and largely prevent alterations in the discharge pattern and in synaptic connectivity induced by central axotomy. Neural progenitor cells are a source of neurotrophic factors and may act as a novel postsynaptic target for the lesioned host neurons. Therefore, we suggest that factors derived from the implanted cells likely play an important role in the re-establishment, to a great extent, of the normal modes of firing and synaptic connectivity in axotomized abducens internuclear neurons.

Acute implantation of cells immediately after lesioning has been shown to be the appropriate method for transplantationbased therapies, since it reduces the secondary tissue damage produced by activated macrophages, while promoting healing (Cusimano et al., 2012). Our strategy was exactly this, as we implanted cells at the lesion site in a single surgical session and in accordance with our previous studies (Pastor et al., 2000; Benítez-Temiño et al., 2005). Moreover, neural progenitor cells isolated from the subventricular germinal zone of kittens could be amplified in vitro as neurospheres, and retained multipotentiality both in vitro and in vivo. The ability to differentiate into cells of different lineages (Reynolds and Weiss, 1992; Lois and Alvarez-Buylla, 1993) indicates a promising therapeutic strategy for restoring function by means of integration and reestablishment of connectivity across the lesion site (Bonner et al., 2011), and by molecular transmittal of signals between host and graft (Li et al., 2006; Tonchev et al., 2007). In our model, we demonstrated the interaction of host axons with grafted cells. Unfortunately, the development of a strategy that promotes crossing of the lesion site by sprouting axons remains to be achieved.

\section{Neural progenitor cells as a source of trophic support for lesioned cells}

Progenitor cells of the subventricular zone express different growth factors, such as NGF, BDNF, NT-3, or VEGF, in their neurogenic niche, as well as when amplified in vitro (Maurer et al., 2003; Tonchev et al., 2007; also our results). They have been useful for the re-establishment of alterations produced by a variety of neuronal lesions (Oka et al., 2004; Fagerlund et al., 2012). Since abducens neurons are endowed with the high-affinity receptors for neurotrophins trkA, trkB, and trkC (Benítez-Temiño et al., 2004), they can retrogradely transport these factors from implanted cells. However, the involvement of these specific neurotrophins in mediating the beneficial effects of these grafts on axotomized abducens internuclear neurons is unlikely. The reason for this is that the firing properties observed in these cells after the implant differed remarkably from those described in the axotomized motoneurons of the same nucleus after the exogenous administration of BDNF, NT-3, or NGF (Davis-López de Carrizosa et al., 2009, 2010). Given that abducens motoneurons and internuclear neurons share similar discharge characteristics and afferent inputs (Delgado-Garcia et al., 1986a,b), they presumably respond similarly to neurotrophins. For example, BDNF and NT-3 produce complementary, albeit differential, effects on the firing and synaptology of axotomized abducens motoneurons. NT-3 produces the re-establishment of the phasic component of firing rate in relation to saccades, whereas BDNF induces restoration of the tonic firing during fixations (Davis-López de Carrizosa et al., 2009). Another neurotrophin with powerful 

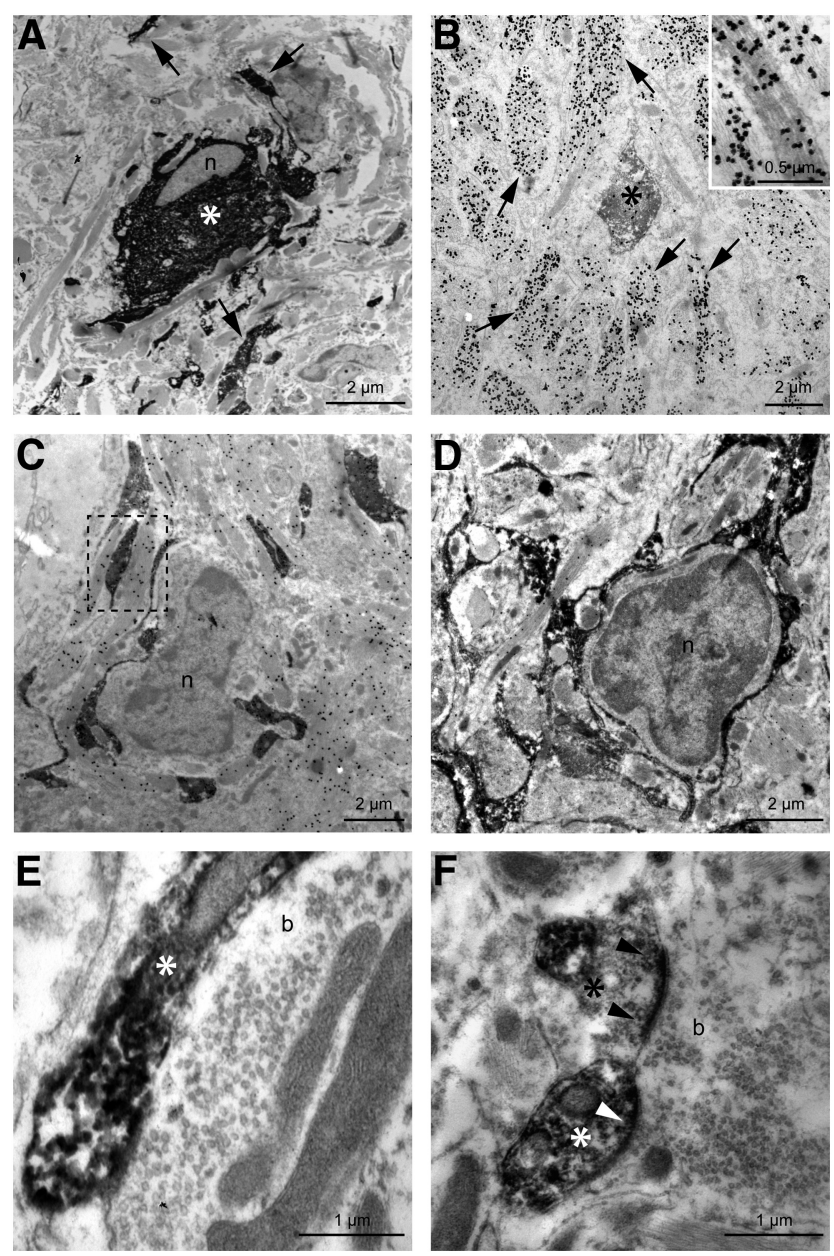

Figure 7. Electron microscopic images showing implanted neural progenitor cells and their relationship with the host tissue. $A$, Soma of a GFP-immunostained neural progenitor cell $\left({ }^{*}\right) ; n$ indicates the cell nucleus. Note other GFP-identified processes in the neuropil (arrows). $\boldsymbol{B}, \mathrm{A}$ GFP-immunoreactive element derived from an implanted cell $\left(^{*}\right)$ surrounded by GFAPimmunostained profiles (arrows). The inset shows at a higher magnification the labeling with immunogold particles of the astrocytic intermediate filaments. C, D, Electron-dense GFP-immunoreactive processes from implanted cells in close apposition to presumptive microglial cells. Note that a thin cytoplasm enveloped the nuclei of the two microglial cells ( $n, C$ and $\boldsymbol{D}$ ). GFAP immunogold labeling revealed the close proximity between host astrocytic processes and implanted elements (e.g., see the framed region in $\boldsymbol{C}$ ). $\boldsymbol{E}, \boldsymbol{F}$, Synaptic boutons (b) in contact with GFPimmunoreactive profiles $\left(^{*}\right)$. Note the postsynaptic densities in the elements derived from implanted neural progenitor cells ( $\boldsymbol{F}$, arrowheads) along with the clustering of synaptic vesicles in the presynaptic terminal, indicative of synaptic contact between host boutons and implanted cells.

synaptotrophic actions on the oculomotor system is NGF. It regulates both the tonic and phasic components of firing (DavisLópez de Carrizosa et al., 2010), but, unlike the present data, it produces a significant increase in $k$ and $r$ values relative to control. Remarkably, neurotrophin-mediated specification of electrophysiological properties has also been found in other systems (Adamson et al., 2002; Zhou et al., 2005; Salama-Cohen et al., 2006).

The physiological response of axotomized abducens internuclear neurons to the implantation of neural progenitor cells was characterized by a complete normalization of the inhibitory eyerelated signals, but only a partial maintenance of the excitatory signals ( $r$-on signals). These findings led us to investigate the possibility that implanted cells contained VEGF, since this factor has been shown to induce a depression in excitatory synaptic

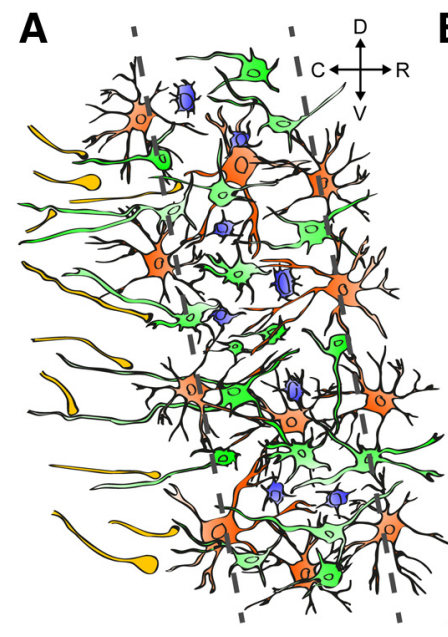

B Control
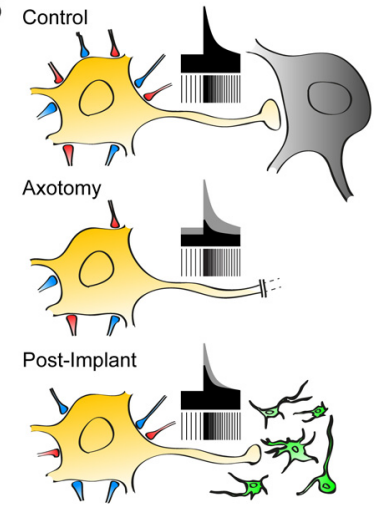

Figure 8. $\quad \boldsymbol{A}, \boldsymbol{B}, \mathrm{Sch}$ ematic drawing summarizing the interactions between implanted neural progenitor cells and the host $(\boldsymbol{A})$ as well as the physiological response of abducens internuclear neurons $(\boldsymbol{B})$. $\boldsymbol{A}$, Scaffold of implanted cells (green) interacting with microglia (blue) and astrocytes (orange). Some sectioned axons in the MLF (yellow) established synaptic contacts with processes originating from implanted cells. D, Dorsal; $C$, caudal; $R$, rostral; V, ventral. $\boldsymbol{B}$, The discharge characteristics and synaptic inputs of abducens internuclear neurons are illustrated. Control cells showed a balance of excitatory to inhibitory synaptic drives, which produced their typical tonic-phasic firing. Axotomy led to the loss of both excitatory and inhibitory boutons in similar proportions, resulting in a decrease in tonic and phasic signals. However, after the implant, axotomized abducens internuclear neurons completely recovered the tonic signals, whereas the re-establishment of the phasic signals was partial and paralleled a synaptic imbalance in favor of inhibition.

transmission in several neuronal types (McCloskey et al., 2005, 2008). Immunostaining demonstrated that $68 \%$ of GFP-positive cells in implanted animals were also VEGF immunoreactive and that the VEGF receptor Flk1 was also present in abducens internuclear neurons. VEGF was discovered as an angiogenic factor, but recent evidence indicates that it also acts as a neurotrophic and neuroprotective agent (Storkebaum et al., 2005; Zachary, 2005; Tolosa et al., 2008; Tovar-Y-Romo and Tapia, 2010). VEGF treatment reduces both astrogliosis and the loss of neuromuscular junctions (Sathasivam, 2008). Moreover, microarray analysis in VEGF-deficient mice shows a downregulation of axonal growth and synapse formation genes (Brockington et al., 2010). Consistent with this, we observed signs of interaction between implanted and host cells, including the establishment of synaptic contacts by MLF axons on neural progenitor cells. Thus, trophic support of lesioned neurons could be delivered retrogradely following uptake by their axonal contacts (Fig. $8 A$, summary of the host-graft interactions at the lesion site).

\section{Changes in excitatory and inhibitory inputs to abducens internuclear neurons}

We have recently shown, in vivo, that neurotrophins are involved in the restoration of diverse components of the firing properties of axotomized motoneurons, and that they exert a potent synaptotrophic action over inputs to motoneurons (Davis-López de Carrizosa et al., 2009, 2010). Those findings demonstrated that firing properties are restored in accordance with the reestablishment of synaptic afferent innervation. It is well known that axotomy induces synaptic denervation and that the intensity of reinnervation is related to the availability of target tissue (Sumner, 1975; de la Cruz et al., 1996). Nonetheless, two major findings here indicate that an imbalance between excitation and inhibition occurred in the axotomized neurons of animals im- 
planted with neural progenitor cells. First, the partial improvement of the $r$-on component of firing (the neuronal eye velocity sensitivity for on-directed saccades), in contrast to the complete restoration of the $r$-off component (Fig. $8 B$, schematic illustration). This implies that the synaptic drive coming from the excitatory reticular burst neurons (responsible for the on-signal) was only partially restored, in contrast to the complete reestablishment of the afferent input from inhibitory reticular burst neurons (Hikosaka et al., 1978; Igusa et al., 1980; Büttner and Büttner-Ennever, 2006). Second, and in agreement with the physiological data, we found a partial re-establisment of synaptophysin coverage (i.e., excitatory plus inhibitory inputs) at the somatic level, whereas the somatic VGAT coverage (only inhibitory synapses) was similar to control values (Fig. $8 B$, synaptic boutons). In interpreting this, it is important to consider that reticular neurons terminate preferentially over the soma and proximal dendrites of abducens neurons (Escudero and Delgado-García, 1988).

On the other hand, the improvement of the tonic firing in abducens internuclear neurons from implanted animals was complete, since $k$ values -including both $k$-on and $k$-off-were similar to their respective control values after grafting. This indicates that the excitatory-to-inhibitory balance of tonic inputs was similar to that of controls. Considering that the tonic input (originating in the prepositus hypoglossi nucleus) terminates preferentially on distal dendrites (Escudero and Delgado-García, 1988), it is noteworthy that the confocal analysis showed normal synaptophysin and VGAT immunoreactivity at the abducens neuropil level.

Two trophic molecules have recently been shown to alter the inhibitory-to-excitatory balance in the direction presented here. NGF effects have been demonstrated for hippocampal neurons (Salama-Cohen et al., 2006) and abducens motoneurons (DavisLópez de Carrizosa et al., 2010), although other changes have also been described in the latter case (i.e., $k$ and $r$ values higher than control values), which were not observed in the present recordings. VEGF has also been shown to alter synaptic and ionic properties of neurons in the direction observed in our data. The synaptic amplitude after Schaffer collateral stimulation in hippocampal neurons or the hypoglossal excitatory responses to solitary tract nucleus stimulation are decreased by VEGF (McCloskey et al., 2005, 2008). The reported depression of excitatory synaptic transmission produced by VEGF could be a form of compensatory plasticity aimed at reducing activity in the epileptic brain (McCloskey et al., 2005). VEGF acts as a pleiotrophic factor on different types of neuronal and glial cells, it fosters neurogenesis and vasculogenesis, and it is axonally transported (Storkebaum et al., 2005). Using the same model, we have previously demonstrated in adult rats that VEGF content in axotomized abducens internuclear neurons increases significantly following neural progenitor cell implants (Talaverón et al., 2013). Thus, although the involvement of other neurotrophic molecules cannot be discarded, our data point to VEGF as a relevant factor mediating the re-establishment of the discharge characteristics in axotomized abducens internuclear neurons, and as a synaptotrophic molecule capable of inducing long-term modifications in the synaptic complement.

In conclusion, the fact that neural progenitor cell implants cause the firing and synaptic properties of injured neurons to depart from the axotomy state and move toward their normal operational mode strongly encourages the use of these cells as a useful tool for inducing functional improvement following trauma or neurological disorders.

\section{References}

Adamson CL, Reid MA, Davis RL (2002) Opposite action of brain-derived neurotrophic factor and neurotrophin-3 on firing features and ion channel composition of murine spiral ganglion neurons. J Neurosci 22:13851396. Medline

Benítez-Temiño B, Morcuende S, Mentis GZ, de la Cruz RR, Pastor AM (2004) Expression of Trk receptors in the oculomotor system of the adult cat. J Comp Neurol 473:538-552. CrossRef Medline

Benítez-Temiño B, de la Cruz RR, Tena JJ, Pastor AM (2005) Cerebellar grafting in the oculomotor system as a model to study target influence on adult neurons. Brain Res Brain Res Rev 49:317-329. CrossRef Medline

Bonner JF, Connors TM, Silverman WF, Kowalski DP, Lemay MA, Fischer I (2011) Grafted neural progenitors integrate and restore synaptic connectivity across the injured spinal cord. J Neurosci 31:4675-4686. CrossRef Medline

Boyce VS, Park J, Gage FH, Mendell LM (2012) Differential effects of brainderived neurotrophic factor and neurotrophin-3 on hindlimb function in paraplegic rats. Eur J Neurosci 35:221-232. CrossRef Medline

Brockington A, Heath PR, Holden H, Kasher P, Bender FL, Claes F, Lambrechts D, Sendtner M, Carmeliet P, Shaw PJ (2010) Downregulation of genes with a function in axon outgrowth and synapse formation in motor neurones of the VEGFdelta/delta mouse model of amyotrophic lateral sclerosis. BMC Genomics 11:203. CrossRef Medline

Büttner U, Büttner-Ennever JA (2006) Present concepts of oculomotor organization. In: Neuroanatomy of the oculomotor system (BüttnerEnnever JA, ed.), pp 1-42. Amsterdam: Elsevier.

Chao MV (2003) Neurotrophins and their receptors: a convergence point for many pathways. Nat Rev Neurosci 4:299-309. CrossRef Medline

Conn G, Bayne ML, Soderman DD, Kwok PW, Sullivan KA, Palisi TM, Hope DA, Thomas KA (1990) Amino acid and cDNA sequences of a vascular endothelial cell mitogen that is homologous to platelet-derived growth factor. Proc Natl Acad Sci U S A 87:2628-2632. CrossRef Medline

Cusimano M, Biziato D, Brambilla E, Donegà M, Alfaro-Cervello C, Snider S, Salani G, Pucci F, Comi G, Garcia-Verdugo JM, De Palma M, Martino G, Pluchino S (2012) Transplanted neural stem/precursor cells instruct phagocytes and reduce secondary tissue damage in the injured spinal cord. Brain 135:447-460. CrossRef Medline

Danscher G, Zimmer J (1978) An improved Timm-shulphide method for light and electron microscopic localization of heavy metals in biological tissues. Histochemistry 55:27-40. CrossRef Medline

Davis-López de Carrizosa MA, Morado-Díaz CJ, Tena JJ, Benítez-Temiño B, Pecero ML, Morcuende SR, de la Cruz RR, Pastor AM (2009) Complementary actions of BDNF and neurotrophin-3 on the firing patterns and synaptic composition of motoneurons. J Neurosci 29:575-587. CrossRef Medline

Davis-López de Carrizosa MA, Morado-Díaz CJ, Morcuende S, de la Cruz RR, Pastor AM (2010) Nerve growth factor regulates the firing patterns and synaptic composition of motoneurons. J Neurosci 30:8308-8319. CrossRef Medline

Davis-López de Carrizosa MA, Morado-Díaz CJ, Miller JM, de la Cruz RR, Pastor AM (2011) Dual encoding of muscle tension and eye position by abducens motoneurons. J Neurosci 31:2271-2279. CrossRef Medline

de la Cruz RR, Pastor AM, Martínez-Guijarro FJ, López-García C, DelgadoGarcía JM (1992) Role of GABA in the extraocular motor nuclei of the cat: a postembedding immunocytochemical study. Neuroscience 51:911929. CrossRef Medline

de la Cruz RR, Pastor AM, Delgado-García JM (1996) Influence of the postsynaptic target on the functional properties of neurons in the adult mammalian central nervous system. Rev Neurosci 7:115-149. Medline

de la Cruz RR, Pastor AM, Martińez-Guijarro FJ, López-García C, DelgadoGarcía JM (1998) Localization of parvalbumin, calretinin, and calbindin D-28k in identified extraocular motoneurons and internuclear neurons of the cat. J Comp Neurol 390:377-391. CrossRef Medline

de la Cruz RR, Delgado-García JM, Pastor AM (2000) Discharge characteristics of axotomized abducens internuclear neurons in the adult cat. J Comp Neurol 427:391-404. CrossRef Medline

de la Cruz RR, Benítez-Temiño B, Pastor AM (2002) Intrinsic determinants of synaptic phenotype: an experimental study of abducens internuclear neurons connecting with anomalous targets. Neuroscience 112:759-771. CrossRef Medline

Delgado-Garcia JM, del Pozo F, Baker R (1986a) Behavior of neurons in the 
abducens nucleus of the alert cat-I. Motoneurons. Neuroscience 17:929952. CrossRef Medline

Delgado-Garcia JM, del Pozo F, Baker R (1986b) Behavior of neurons in the abducens nucleus of the alert cat-II. Internuclear neurons. Neuroscience 17:953-973. CrossRef Medline

Ernfors P, Ibáñez CF, Ebendal T, Olson L, Persson H (1990) Molecular cloning and neurotrophic activities of a protein with structural similarities to nerve growth factor: developmental and topographical expression in the brain. Proc Natl Acad Sci U S A 87:5454-5458. CrossRef Medline

Escudero M, Delgado-García JM (1988) Behavior of reticular, vestibular and prepositus neurons terminating in the abducens nucleus of the alert cat. Exp Brain Res 71:218-222. Medline

Fagerlund M, Pérez Estrada C, Jaff N, Svensson M Brundin L (2012) Neural stem/progenitor cells transplanted to the hypoglossal nucleus integrates with the host CNS in adult rats and promotes motor neuron survival. Cell Transplant 21:739-747. CrossRef Medline

Fuchs AF, Robinson DA (1966) A method for measuring horizontal and vertical eye movement chronically in the monkey. J Appl Physiol 21: 1068-1070. Medline

González-Forero D, Pastor AM, Delgado-García JM, de la Cruz RR, Alvarez FJ (2004) Synaptic structural modification following changes in activity induced by tetanus neurotoxin in cat abducens neurons. J Comp Neurol 471:201-218. CrossRef Medline

Gudiño-Cabrera G, Pastor AM, de la Cruz RR, Delgado-García JM, NietoSampedro M (2000) Limits to the capacity of transplants of olfactory glia to promote axonal regrowth in the CNS. Neuroreport 11:467-471. CrossRef Medline

Hikosaka O, Igusa Y, Nakao S, Shimazu H (1978) Direct inhibitory synaptic linkage of pontomedullary reticular burst neurons with abducens motoneurons in the cat. Exp Brain Res 33:337-352. Medline

Igusa A, Sasaki S, Shimazu H (1980) Excitatory premotor burst neurons in the cat pontine reticular formation related to the quick phase of vestibular nystagmus. Brain Res 182:451-456. CrossRef Medline

Lein ES, Hohn A, Shatz CJ (2000) Dynamic regulation of BDNF and NT-3 expression during visual system development. J Comp Neurol 420:1-18. CrossRef Medline

Li J, Imitola J, Snyder EY, Sidman RL (2006) Neural stem cells rescue nervous Purkinje neurons by restoring molecular homeostasis of tissue plasminogen activator and downstream targets. J Neurosci 26:7839-7848. CrossRef Medline

Lois C, Alvarez-Buylla A (1993) Proliferating subventricular zone cells in the adult mammalian forebrain can defferentiate into neurons and glia. Proc Natl Acad Sci U S A 90:2074-2077. CrossRef Medline

Maisonpierre PC, Le Beau MM, Espinosa R 3rd, Ip NY, Belluscio L, de la Monte SM, Squinto S, Furth ME, Yancopoulos GD (1991) Human and rat brain-derived neurotrophic factor and neurotrophin-3: gene structures, distributions, and chromosomal localizations. Genomics 10:558568. CrossRef Medline

Maurer MH, Tripps WK, Feldmann RE Jr, Kuschinsky W (2003) Expression of vascular endothelial growth factor and its receptors in rat neural stem cells. Neurosci Lett 344:165-168. CrossRef Medline

McCloskey DP, Croll SD, Scharfman HE (2005) Depression of synaptic transmission by vascular endothelial growth factor in adult rat hippocampus and evidence for increased efficacy after chronic seizures. J Neurosci 25:8889-8897. CrossRef Medline

McCloskey DP, Hintz TM, Scharfman HE (2008) Modulation of vascular endothelial growth factor (VEGF) expression in motor neurons and its electrophysiological effects. Brain Res Bull 76:36-44. CrossRef Medline

Morcuende S, Matarredona ER, Benítez-Temiño B, Muñoz-Hernández R, Pastor AM, de la Cruz RR (2011) Differential regulation of the expression of neurotrophin receptors in rat extraocular motoneurons after lesion. J Comp Neurol 519:2335-2352. CrossRef Medline

Navarro X, Vivó M, Valero-Cabré A (2007) Neural plasticity after peripheral nerve injury and regeneration. Prog Neurobiol 82:163-201. CrossRef Medline

Oka S, Honmou O, Akiyama Y, Sasaki M, Houkin K, Hashi K, Kocsis JD (2004) Autologous transplantation of expanded neural precursor cells into the demyelinated monkey spinal cord. Brain Res 1030:94-102. CrossRef Medline

Park H, Poo MM (2013) Neurotrophin regulation of neural circuit development and function. Nat Rev Neurosci 14:7-23. CrossRef Medline
Pastor AM, Gonzalez-Forero D (2003) Recruitment order of cat abducens motoneurons and internuclear neurons. J Neurophysiol 90:2240-2252. CrossRef Medline

Pastor AM, Moreno-López B, de la Cruz RR, Delgado-García JM (1997) Effects of botulinum neurotoxin type A on abducens motoneurons in the cat: ultrastructural and synaptic alterations. Neuroscience 81:457-478. CrossRef Medline

Pastor AM, Delgado-García JM, Martínez-Guijarro FJ, López-García C, de la Cruz RR (2000) Response of abducens internuclear neurons to axotomy in the adult cat. J Comp Neurol 427:370-390. CrossRef Medline

Reynolds BA, Weiss S (1992) Generation of neurons and astrocytes from isolated cells of adult mammalian central nervous system. Science 255 : 1707-1710. CrossRef Medline

Rind HB, Butowt R, von Bartheld CS (2005) Synaptic targeting of retrogradely transported trophic factors in motoneurons: comparison of glial cell line-derived neurotrophic factor, brain-derived neurotrophic factor and cardiotrophin-1 with tetanus toxin. J Neurosci 25:539-549. CrossRef Medline

Ruiz de Almodovar C, Fabre PJ, Knevels E, Coulon C, Segura I, Haddick PC, Aerts L, Delattin N, Strasser G, Oh WJ, Lange C, Vinckier S, Haigh J, Fouquet C, Gu C, Alitalo K, Castellani V, Tessier-Lavigne M, Chedotal A, Charron F, Carmeliet P (2011) VEGF mediates commissural axon chemoattraction through its receptor Flk1. Neuron 70:966-978. CrossRef Medline

Salama-Cohen P, Arévalo MA, Grantyn R, Rodríguez-Tébar A (2006) Notch and GF/p75NTR control dendrite morphology and the balance of excitatory/inhibitory synaptic input to hippocampal neurones through Neurogenin 3. J Neurochem 97:1269-1278. CrossRef Medline

Sathasivam S (2008) VEGF and ALS. Neurosci Res 62:71-77. CrossRef Medline

Storkebaum E, Lambrechts D, Dewerchin M, Moreno-Murciano MP, Appelmans S, Oh H, Van Damme P, Rutten B, Man WY, De Mol M, Wyns S, Manka D, Vermeulen K, Van Den Bosch L, Mertens N, Schmitz C, Robberecht W, Conway EM, Collen D, Moons L, Carmeliet P (2005) Treatment of motoneuron degeneration by intracerebroventricular delivery of VEGF in a rat model of ALS. Nat Neurosci 8:85-92. CrossRef Medline

Sumner BE (1975) An ultrastructural study of normal and injured hypoglossal nuclei after injection of horseradish peroxidase. Exp Brain Res 23:463-470. Medline

Talaverón R, Matarredona ER, de la Cruz RR, Pastor AM (2013) Neural progenitor cell implants modulate vascular endothelial growth factor and brain-derived neurotrophic factor expression in rat axotomized neurons. PLoS One 8:e54519. CrossRef Medline

Titmus MJ, Faber DS (1990) Axotomy-induced alterations in the electrophysiological characteristics of neurons. Prog Neurobiol 35:1-51. CrossRef Medline

Tolosa L, Mir M, Asensio VJ, Olmos G, Lladó J (2008) Vascular endothelial growth factor protects spinal cord motoneurons against glutamateinduced excitotoxicity via phosphatidylinositol 3-kinase. J Neurochem 105:1080-1090. CrossRef Medline

Tonchev AB, Yamashima T, Guo J, Chaldakov GN, Takakura N (2007) Expression of angiogenic and neurotrophic factors in the progenitor cell niche of adult monkey subventricular zone. Neuroscience 144:14251435. CrossRef Medline

Tovar-Y-Romo LB, Tapia R (2010) VEGF protects spinal motor neurons against chronic exciototoxic degeneration in vivo by activation of the PI3-K pathway and inhibition of p38MAPK. J Neurochem 115:10901101. CrossRef Medline

Whittemore SR, Friedman PL, Larhammar D, Persson H, Gonzalez-Carvajal M, Holets VR (1988) Rat beta-nerve growth factor sequence and site of synthesis in the adult hippocampus. J Neurosci Res 20:403-410. CrossRef Medline

Wisden W, Morris BJ (2002) In situ hybridization with oligonucleotide probes. Int Rev Neurobiol 47:3-59. CrossRef Medline

Zachary I (2005) Neuroprotective role of vascular endothelial growth factor: signalling mechanisms, biological function, and therapeutical potential. Neurosignals 14:207-221. CrossRef Medline

Zhou Z, Liu Q, Davis RL (2005) Complex regulation of spiral ganglion neuron firing patterns by neurotrophin-3. J Neurosci 25:7558-7566. CrossRef Medline 